\title{
Notes on two species of the genus Atemnus Canestrini (Pseudoscorpiones: Atemnidae) from China
}

\author{
Jun-fang $\mathrm{Hu}^{1}$ \& Feng Zhang ${ }^{2}$ \\ 1,2 College of Life Sciences, Hebei University, Baoding, Hebei 071002 China \\ Email: ${ }^{1}$ jfanghu@gmail.com, ${ }^{2}$ dudu06042001@163.com (corresponding author)
}

\begin{abstract}
Two pseudoscorpion species of the genus Atemnus Canestrini, 1884 are reported from China: $A$. limuensis sp. nov. from the Ormosia tree bark in a humid tropical forest and $A$. politus Simon, 1878 from leaf litter in a temperate deciduous forest. A key to all known species of this genus is provided.
\end{abstract}

Keywords: Atemnus, China, new species, pseudoscorpions, taxonomy.

The pseudoscorpion family Atemnidae Kishida, 1929 (see Judson 2010) is divided into two subfamilies and 19 genera, with four species and four genera from China (Atemnus Canestrini, 1884, Anatemnus Beier, 1932 and Paratemnoides Harvey, 1991 of the subfamily Atemninae Kishida, 1929 and Diplotemnus Chamberlin, 1933 of the subfamily Miratemninae Beier, 1932). Atemnus Canestrini, 1884 is the type genus of Atemnidae and includes five species: Atemnus letourneuxi (Simon, 1881) from northern Africa and Yemen, A. neotropicus Hoff, 1946 from the Carribean

Date of publication (online): 26 September 2012 Date of publication (print): 26 September 2012 ISSN 0974-7907 (online) | 0974-7893 (print)

Editor: Volker Mahnert

\section{Manuscript details:}

Ms \# 03049

Received 26 December 2011

Final received 12 August 2012

Finally accepted 27 August 2012

Citation: Hu, J-f. \& F. Zhang (2012). Notes on two species of the genus Atemnus Canestrini (Pseudoscorpiones: Atemnidae) from China. Journal of Threatened Taxa 4(11): 3059-3066.

Copyright: () Jun-fang Hu \& Feng Zhang 2012. Creative Commons Attribution 3.0 Unported License. JoTT allows unrestricted use of this article in any medium for non-profit purposes, reproduction and distribution by providing adequate credit to the authors and the source of publication.

Acknowledgements: We are grateful to Prof. Mark S. Harvey (Western Australian Museum, Perth, Australia) and Prof. Volker Mahnert (Museum of Natural History, Geneva, Switzerland) for their invaluable comments and many helps on this text. Many thanks are given to Prof. Xin-ping Wang for his generous helps to improve the grammar in this text. This work was supported by the National Natural Science Foundation of China (Nos. 30970325, 31071885, 31093430).

\section{OPEN ACGESS | FREE DOWNLOAD}

region, A. strinatii Beier, 1977 from the Philippines, A. syriacus (Beier, 1955) from Europe and the Middle East, and A. politus (Simon, 1878) widely distributed from Europe and northern Africa to Asia, including China (Harvey 2011).

With support from the National Natural Science Foundation of China, the authors began to collect and study Chinese pseudoscorpions in 2007. Two Atemnus species have been found in our collection, including a new Atemnus species from Hainan, which differs morphologically from other Atemnus species in China and $A$. politus from Shanxi Province. In this paper, we describe the new species and provide a detailed description of $A$. politus based on the material from Shanxi, China.

\section{Materials and Methods}

The material was preserved in $75 \%$ alcohol. The description and terminology follow Chamberlin (1931) and Judson (2007). Terminology of genitalia follows Klausen (2005). All measurements are given in millimetres. Drawings were made with the aid of a prism mounted above the eyepiece of a compound microscope. Photographs were taken with a Leica M165c stereomicroscope. Detailed examination was carried out with a Nikon YS100 general optical microscope. Temporary slide mounts were made in glycerol. The specimens referred here are deposited in the Museum of Hebei University (MHBU), Baoding City, China.

Abbreviations: Trichobothria: $b=$ basal; $s b=$ sub-basal; $s t=$ sub-terminal; $t=$ terminal; $i b=$ interior basal; is $b=$ interior subbasal; ist = interior sub-terminal; it = interior terminal; eb = exterior basal; esb = exterior sub-basal; est = exterior sub-terminal; et = exterior terminal. Male genitalia: $\mathrm{a}=$ lateral apodeme; $\mathrm{b}=$ hooked branch; $c$ = sclerotized bar; $d=$ longitudinal fold of medial diverticulum; $e=$ ejaculatory canal atrium; $f=$ lateral rods; $g=$ dorsal apodeme; $\mathrm{h}$ = ventral diverticulum; $\mathrm{I}=$ lateral lip of lateral apodeme. 


\section{Results}

Genus Atemnus Canestrini, 1884

For synonymies see Harvey (2011).

Type species: Atemnus politus (Simon, 1878).

Diagnosis: See (Beier 1932a,b; Murthy \& Ananthakrishnan 1977).

Remarks: Atemnus, the type genus of Atemnidae, is similar to Anatemnus in having a similar pedipalpal patella, but can be distinguished by the trichobothrial pattern on the fixed finger: the distance between est and esb is the same as that between ist and isb in Atemnus, but longer in Anatemnus. The definition of atemnid genera has long been based on external characters only. Klausen (2005) studied the male genitalia of 44 Atemninae and Miratemninae species and concluded that the present generic delimitation was not reliable. As a result, the male genital structures are also explored, in addition to the external characters. The major differences between the two genera Atemnus and Anatemnus can also be found in the male genital organ (Klausen 2005, p.658, figs 9, 23-25).

\section{Atemnus politus (Simon, 1878)}

$$
\text { (Image 1, Fig. 1) }
$$

For synonymies see Harvey (2011).

Material examined: 02.viii.2010, five males (Ps.MHBU-SX10080201-10080205) and five females (Ps.-MHBU-SX10080206-10080210) from China, Shanxi Province, Licheng City, Huangyadong Forest Park $\left(36.80^{\circ} \mathrm{N} \& 113.45^{\circ} \mathrm{E}\right), 757 \mathrm{~m}$, coll. Sheng-tao Guo leg.

Diagnosis: Atemnus politus is characterized by the granulate medial face of the pedipalpal femur and patella, the presence of a round dorsal tubercle on the trochanter, and the relatively small size of chela with pedicel (male 1.15-1.33 mm, female 1.30-1.35 mm).

Description: Pedipalps and the anterior half of carapace deep brown, tergites yellow (Image 1). Setae on body and legs apically dentate.

Carapace smooth (Fig. 1A), without furrow and longer than broad $(1.12 \times$ in male and $1.04-1.07 \times$ in female); with distinct eyespots; 38-42 setae in total, of which 6 on anterior margin and 6-8 on posterior margin; the anterior half darker than the posterior half.

Abdomen tergites IV-X incompletely divided, half-tergites with 4-6 marginal setae. Tergal chaetotaxy: 6-8 : 6-8:8:10-12:10-11:10-11 :

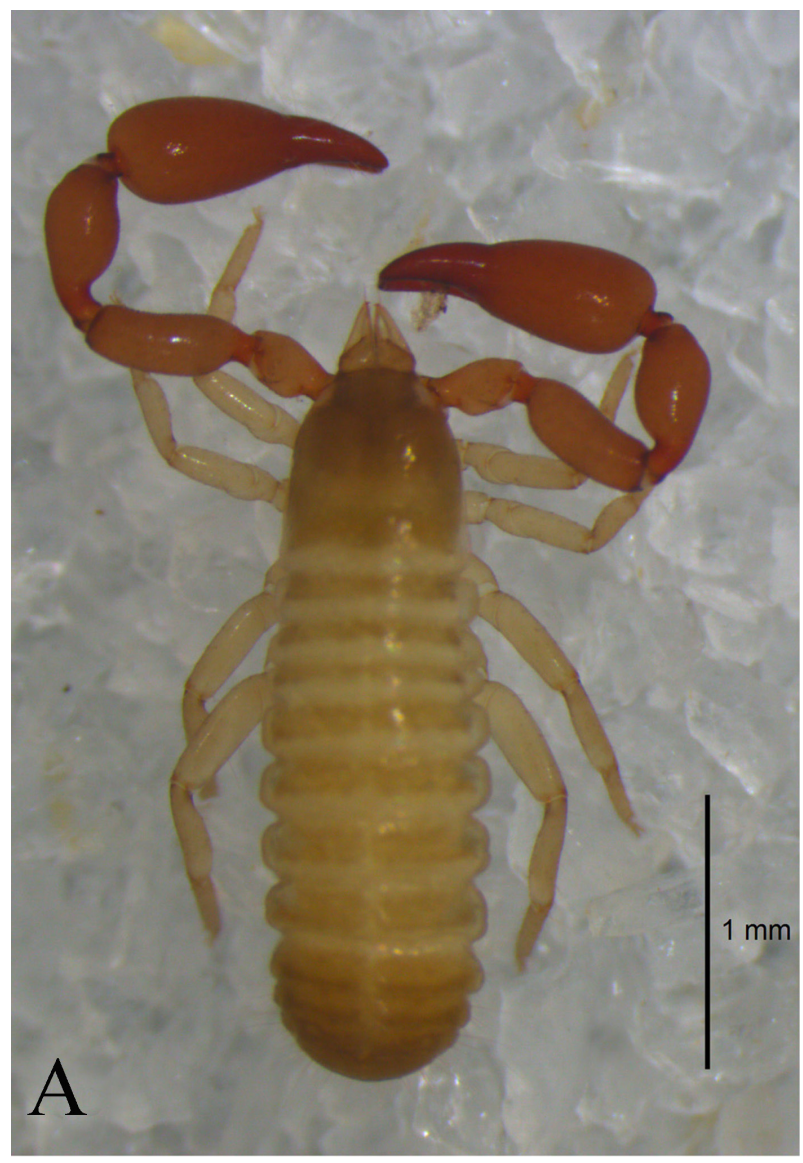

Image 1. Atemnus politus: female habitus, dorsal view.

$11-12: 12: 12: 10-12(4 \mathrm{~T}): 8(2 \mathrm{~T}): 2$; sternites IV-VIII divided, half-sternites with $5-8$ setae, sternal chaetotaxy (IV-XI) : 9-11 : 11-14 : 12-13 : 12-14 : 12-14 : 12-15:10-12 (4T) : 8-10 (4T) : 2. Anterior genital operculum of male (Fig. 1J) with 9-10 setae on each side and 10 on posterior margin; that of female (Fig. 1H) with 10-12 setae on anterior genital operculum and 2-3 lyrifissures, and with 9-10 setae on posterior margin. Male genital structure (Fig. 1K): the distal part (1) of lateral apodemes is relatively smaller, and the hooked branch (b) is bowed distally and terminates in a plate-like tip, the proximal part has a distinct dark sclerotized bar (c); the longitudinal fold of medial diverticula (d) has a projection midway along its length; the ejaculatory canal atrium (e) not well-developed; the lateral rods (f) long and diverging proximally; the tip of dorsal apodeme ( $\mathrm{g}$ ) completely joined; the ventral diverticulum (h) bilobed. Female genital structure (Fig. 1D) simple, spermathecae provided with separated median cribriform plates.

Cheliceral hand with four setae, $b s$ and es short 

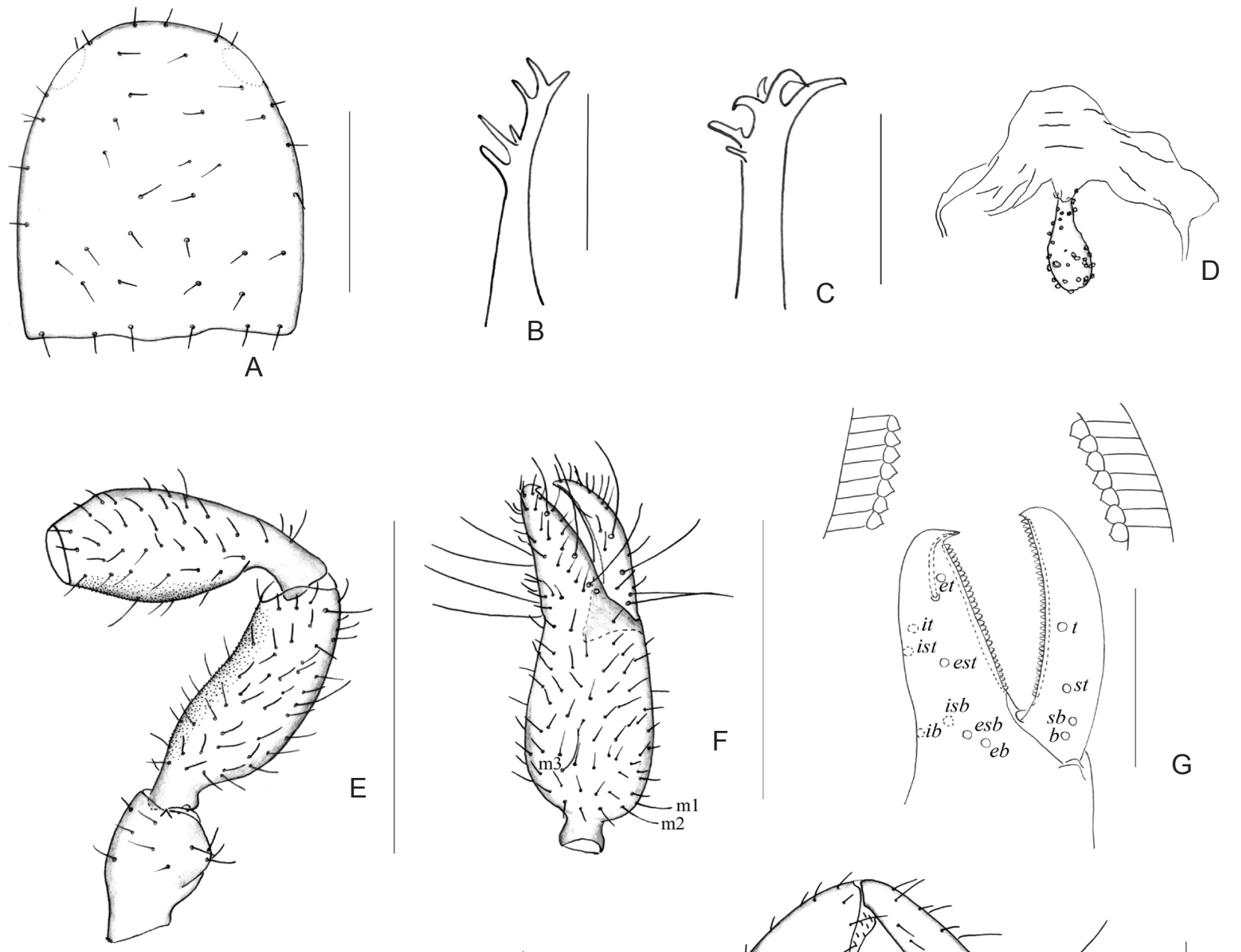

G
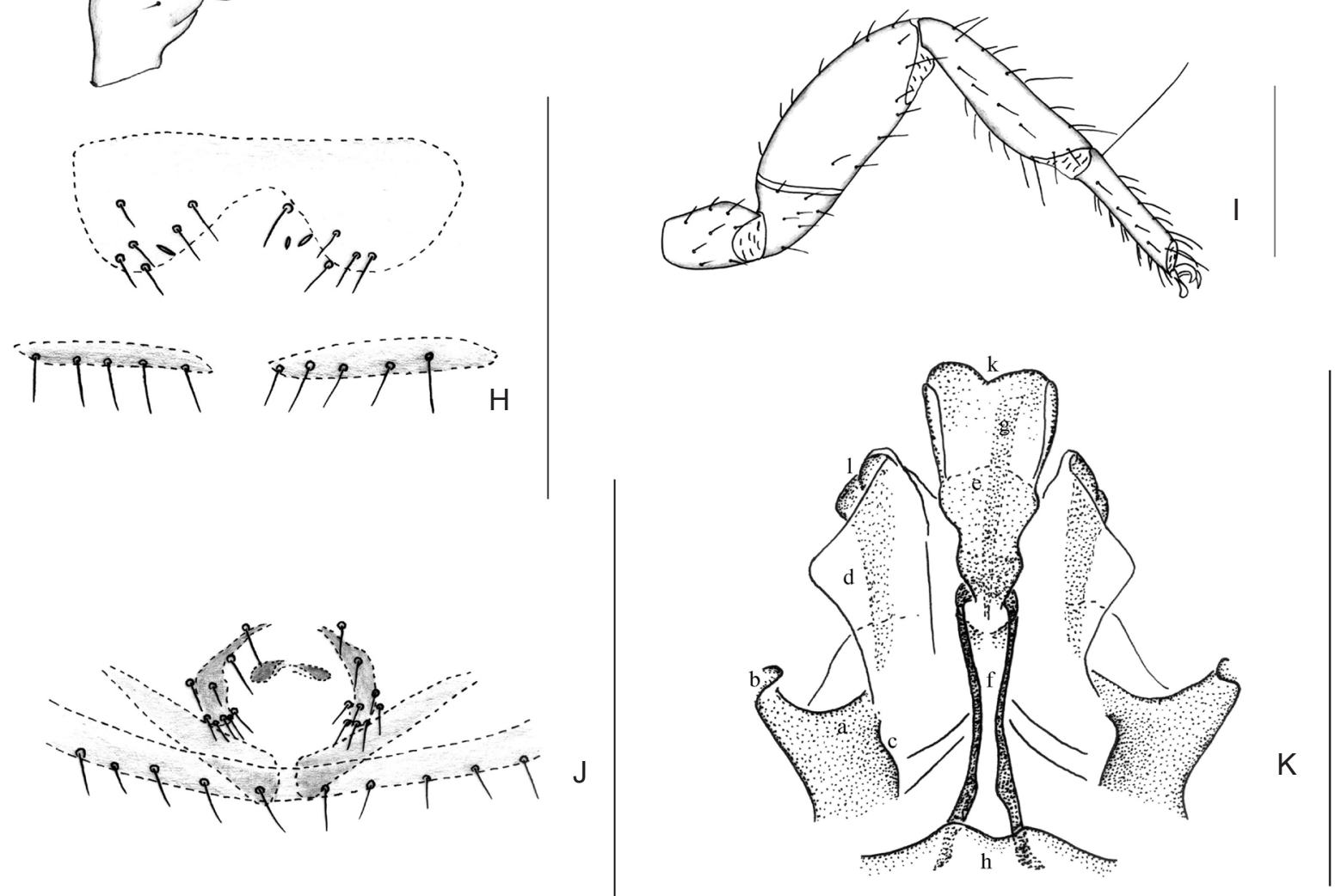

Figure 1. Atemnus politus.

A - Male carapace, dorsal view; B - Male galea; C - Female galea; D - Spermatheca; E - Male pedipalp (minus chela), dorsal view; F - Male chela, lateral view; G - Male chelal fingers, lateral view; H - Female genital area; I - Leg IV; J - Male genital area; K - Male genital organ. Scale lines: 1.0mm (Figs. E-F), 0.5mm (Figs. A, I), 0.4 mm (Figs. D, G-H, J-K), 0.05mm (Figs. B-C). 
and finely dentate, and $i$ and $l s$ long and acute, fixed finger with four retrorse teeth and three small apical teeth, movable finger with a long, tooth-like subapical lobe, male galea (Fig. 1B) relatively short and with six branchelets and female galea (Fig. 1C) long and with 5-6 distinct branchelets, of which the basal one rebranched, serrula exterior 21-25 lamellae, rallum of four setae, only the distal one dentate anteriorly.

Pedipalp: trochanter 1.72-1.74, femur 2.50-2.67, patella $2.19-2.23$, chela with pedicel $3.03-3.09$, chela without pedicel 2.82-2.91, hand without pedicel $1.68-1.70 \times$ longer than broad, and movable finger 0.59-0.71 $\times$ longer than hand (female trochanter 1.43-1.50, femur 2.67-2.86, patella 1.97-2.09, chela with pedicel $2.70-2.77$, chela without pedicel $2.46-$ 2.55, hand without pedicel 1.50-1.55 $\times$ longer than broad, and movable finger $0.75-0.77 \times$ longer than hand). The prolateral face of pedipalpal femur and patella strongly granulate (Figs. 1E-F); trochanter with distinct round dorsal protuberance, fixed finger (Fig. 1G) with 29-30 cusped marginal teeth, movable finger with 35 marginal teeth, venom duct short, ramosus nodus between trichobothria et and it, but near et. Trichobothrial pattern: st on movable finger nearly between $t$ than $s b$; on fixed finger distance of est removed from $e s b$ same as ist and $i s b, i t$ from finger tip nearly equals to distance between ist and isb.

Legs fairly stout, without granular, claws simple and longer than arolia, subterminal seta acute and curved. Tactile seta on tarsus IV (Fig. 2I) situated near the base (TS $=0.12)$.

Dimensions (length/breadth or depth, in $\mathbf{~ m m}$ ): Male. Body length: 2.55-2.61. Carapace 0.75-0.84 / 0.67-0.75 (1.12); pedipalp: trochanter $0.40-0.43$ / $0.23-0.25$ (1.72-1.74), femur $0.70-0.80 / 0.28-0.30$ (2.50-2.67), patella $0.70-0.78 / 0.32-0.35(2.19-2.23)$, chela with pedicel 1.15-1.33 / 0.38-0.43 (3.03-3.09), chela without pedicel $1.07-1.25$ (2.82-2.91), hand without pedicel $0.64-0.73(1.68-1.70)$, movable finger length $0.43-0.52(0.59-0.71 \times$ hand $)$; leg I: femur $0.23-0.25 / 0.15-0.18(1.39-1.53)$, patella $0.38-0.40$ / $0.14-0.18$ (2.22-2.71), tibia $0.40 / 0.10-0.11$ (3.64 4.00), tarsus $0.38-0.40 / 0.08-0.10(4.00-4.75)$; leg IV: femur + patella $0.70-0.80 / 0.23-0.25(3.04-3.20)$, tibia $0.53-0.60 / 0.15-0.18(3.33-3.53)$, tarsus 0.40 $0.43 / 0.10-0.12(3.58-4.00)$.

Female. Body length: 3.38-3.47. Carapace $0.80 /$ $0.75-0.77$ (1.04-1.07); pedipalp: trochanter $0.42-0.43$
/ $0.28-0.30$ (1.43-1.50), femur 0.80 / 0.28-0.30 (2.67$2.86)$, patella $0.73-0.75 / 0.35-0.38(1.97-2.09)$, chela with pedicel 1.30-1.35 / 0.47-0.50 (2.70-2.77), chela without pedicel 1.20-1.23 (2.46-2.55), hand without pedicel $0.73-0.75(1.50-1.55)$, movable finger length $0.55-0.58(0.75-0.77 \times$ hand $)$; leg I: femur $0.28-0.35$ / 0.15-0.18 (1.87-1.94), patella $0.38-0.40 / 0.15-0.18$ (2.22-2.53), tibia $0.38-0.43 / 0.10-0.13(3.31-3.80)$, tarsus $0.33-0.40 / 0.08-0.10(4.00-4.13)$; leg IV: femur + patella $0.73-0.80 / 0.23-0.25(3.17-3.20)$, tibia $0.55-0.60 / 0.15-0.18(3.33-3.67)$, tarsus $0.43-$ $0.45 / 0.10-0.12(3.75-4.30)$.

Distribution: China (Shanxi).

Habitat: The specimens of A. politus were collected from leaf litter in a temperate deciduous forest.

Remarks: Atemnus politus was first reported from China by Beier (1967). The male genital structures of the specimens from Shanxi Province fit A. politus illustrated by Klausen (2005). In addition, the dimensions and proportions are rather consistent with those of A. politus given by Beier (1932a, b; 1963) and Dashdamirov \& Schawaller (1992). Based on the external morphological characters and male genital characters, we believe the material from Shanxi, China belonging to $A$. politus.

\section{Atemnus limuensis sp. nov.} (Image 2, Fig. 2)

Type material: 07.v.2011, holotype male (Ps.MHBU-HN11050701) from China, Hainan Province, Mt. Limu $\left(19.17^{\circ} \mathrm{N} \& 109.74^{\circ} \mathrm{E}\right)$, together with five males (Ps.-MHBU-HN11050702- 11050706), nine females (Ps.-MHBU-HN11050707- 11050716) paratypes, coll. Junfang Hu leg.

Etymology: The specific name is derived from the type locality.

Diagnosis: This new species can be recognized by the following combination of characters: carapace with two distinct eyespots; body in large size (male 4.384.88, female 5.40-6.25); retrolateral face of pedipalpal trochanter, prolateral face of pedipalpal femur and patella, and basal fingers distinctly granulate; dorsal and retrolateral face of trochanter with coniform tubercles; carapace covered with numerous setae.

Description: Pedipalps and the anterior half of carapace reddish-brown (Image 2), tergites brown. Setae on body and legs apically dentate.

Carapace smooth, without furrow, longer than broad 


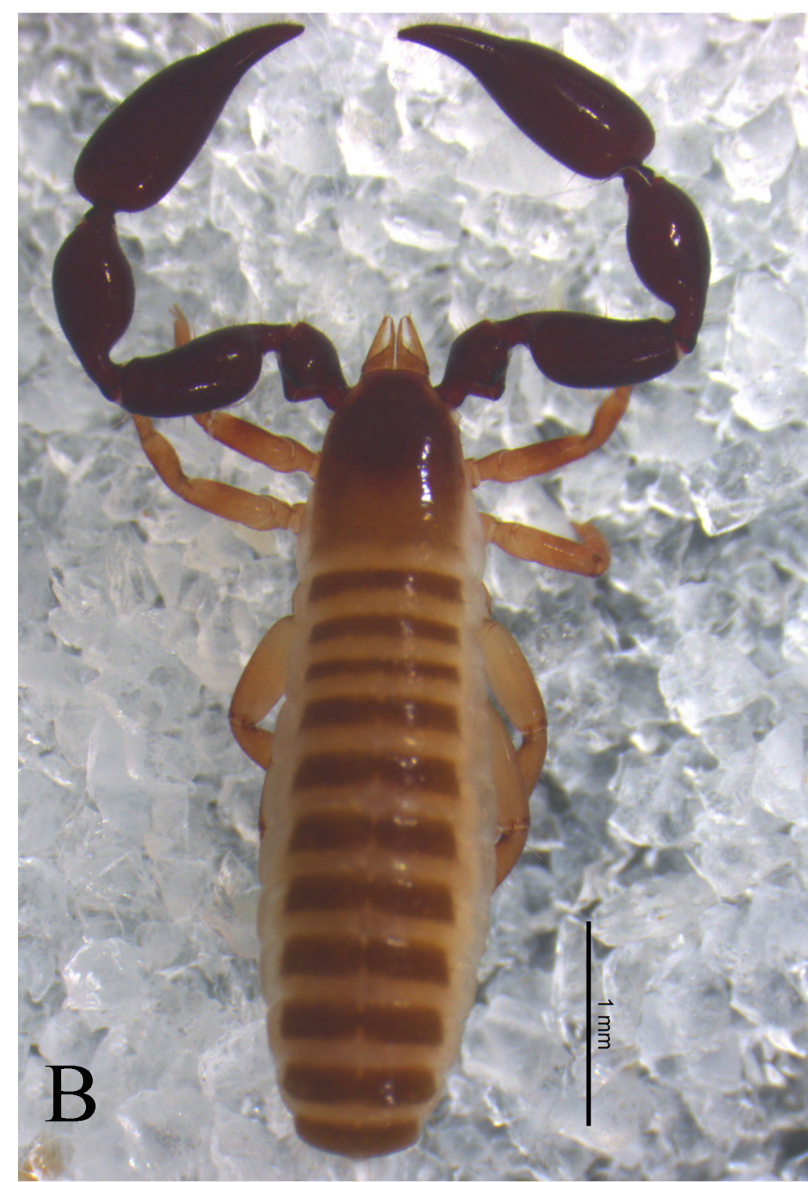

Image 2. Atemnus limuensis sp. nov.: male habitus, dorsal view.

(1.16-1.20 $\times$ in male and $1.20-1.32 \times$ in female); with distinct eyespots (Fig. 2A); 68-72 setae, with four on anterior margin and 8-10 on posterior margin; the anterior half darker than the posterior half.

Abdomen all tergites incompletely divided, halftergites with 4-9 marginal setae. Tergal chaetotaxy: 8-11 : 8-11 : 9-11 : 12-16:14-18:16-17: 16-17 : 16-17: 16-17 : 14-17 (4T) : 11-13 (4T) : 2; sternites divided, half-sternites with $6-10$ setae, sternal chaetotaxy (IV - XI) : 16-17 : 18-19 : 17-18 : 17-18 $: 18-20: 16-19: 12-18(4 \mathrm{~T}): 13(4 \mathrm{~T}): 2$. Anterior genital operculum of male (Fig. $2 \mathrm{G}$ ) with $8-9$ setae on each side and 10-11 on posterior margin; that of female (Fig. 2J) with 8-10 setae on anterior genital operculum and 8-10 setae on posterior margin. Male genital structure (Fig. 2K): the hooked branch (b) bowed distally, terminated in a relatively small platelike tip, with a distinct dark sclerotized bar proximally (c); the longitudinal folder of medial diverticula (d) with a projection medially and a prominent extension along the sagittal plane, forming M-shape bulge (k); the ejaculatory canal atrium (e) crescent-shaped on both sides and the distal end of the atrium procurved; the lateral rods (f) long and diverging proximally; the tip of dorsal apodeme $(\mathrm{g})$ completely joined; the ventral diverticulum (h) bilobed. Female genital structure (Fig. 2I) simple, spermathecae with separated median cribriform plate.

Cheliceral hand with four setae (Fig. 2B), bs and es short and finely dentated, $i s$ and $l s$ long and acute, fixed finger with four retrorse teeth and 2-3 small apical teeth, movable finger with a long, tooth-like subapical lobe, male galea (Fig. 2C) relatively short, with 6-7 branchelets, female galea (Fig. 2D) long, with 5-6 distinct branchelets, of which the basal one rebranched, serrula exterior 27-28 lamellae, rallum (Fig. 2E) of 4 setae, only the distal one dentated anteriorly.

Pedipalp: trochanter 1.10-1.30, femur 2.22-2.55, patella $2.12-2.18$, chela with pedicel $2.97-3.10$, chela without pedicel $2.73-2.84$, hand without pedicel 1.711.72 longer than broad, and movable finger $0.59-0.63 \times$ longer than hand (female trochanter 1.43-1.50, femur 2.27-2.38, patella $1.92-2.02$, chela with pedicel $2.77-$ 2.92, chela without pedicel 2.49-2.58, hand without pedicel 1.58-1.67 longer than broad, and movable finger $0.63 \times$ longer than hand). The retrolateral face of pedipalpal trochanter (Fig. 2L), prolateral face of pedipalpal femur and patella, and the basal fingers strongly granulated; trochanter with distinct coniform and granulated protuberances, fixed finger (Fig. 2H) with 29-30 cusped marginal teeth, movable finger with 35-36 marginal teeth, venom duct short, ramosus nodus medially between trichobothria et and it. Trichobothrial pattern: $s t$ on movable finger between $t$ than $s b$; on fixed finger est at the level of ist, distance of $e s t$ and $e s b$ same as ist and isb, it from finger tip nearly equals to distance between ist and $i s b$.

Legs fairly stout and smooth, claws simple, longer than arolia, subterminal seta acute and curved. Tactile seta on tarsus IV (Fig. 2F) situated proximally (TS = $0.20)$.

Dimensions (length/breadth or depth, in $\mathbf{m m}$ ): Male: Body length: 4.38-4.88. Carapace 1.10-1.20/ 0.95-1.00 (1.16-1.20); pedipalp: trochanter $0.50-0.65$ / 0.45-0.50 (1.10-1.30), femur 1.00-1.20 / 0.45-0.47 (2.22-2.55), patella 1.10-1.20/0.52-0.55 (2.12-2.18), chela with pedicel 1.80-1.90 / 0.58-0.64 (2.97-3.10), chela without pedicel 1.65-1.75 (2.73-2.84), hand 


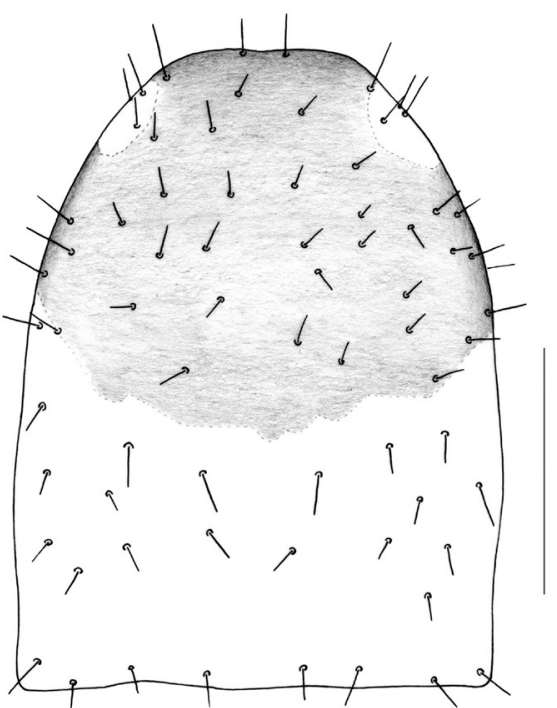

A
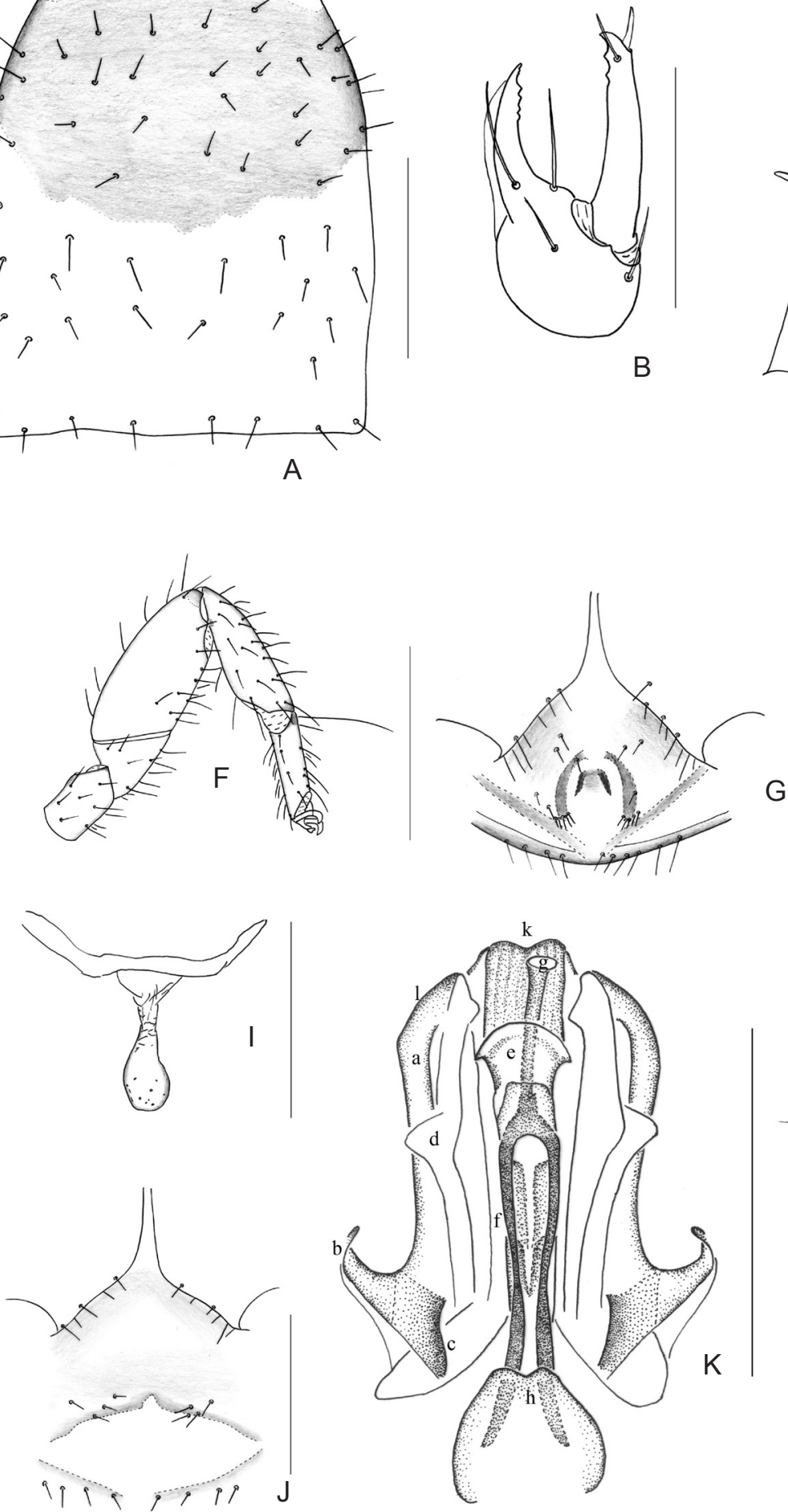
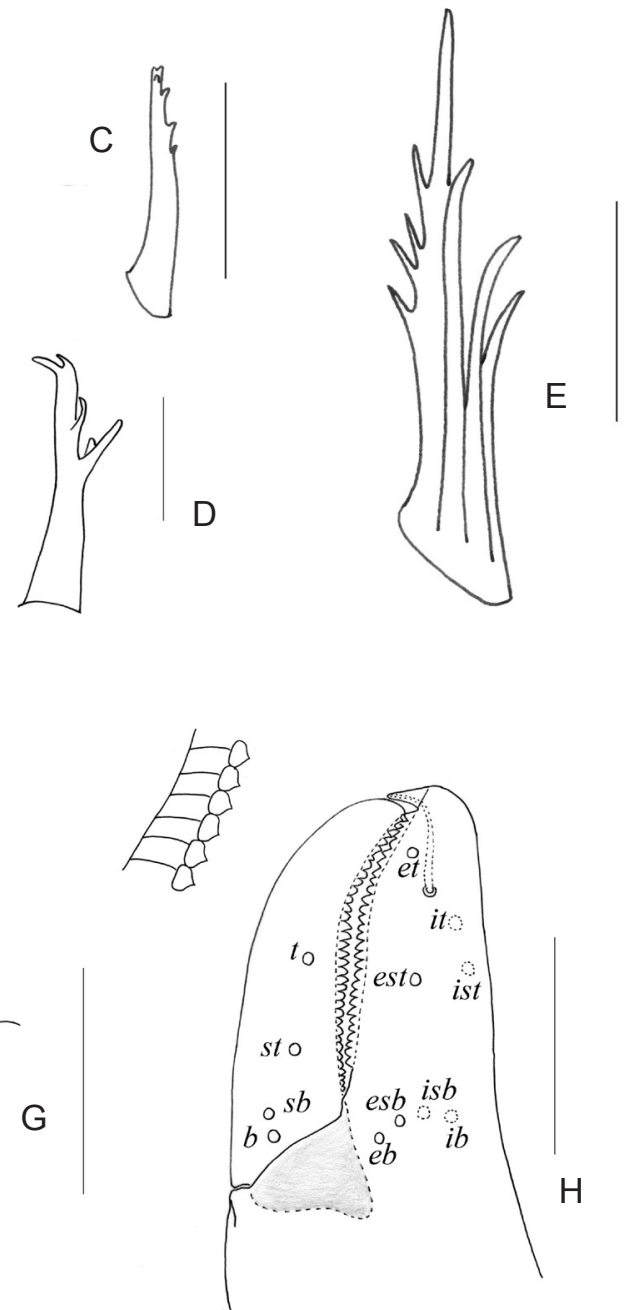

Figure 2. Atemnus limuensis sp. nov.

A - Male carapace, dorsal view; B - Male chelicera, dorsal view; C - Male galea; D - Female galea; E - Rallum; F - Leg IV; G - Male genital area; H - Male chelal fingers, lateral view; I - Spermatheca; J - Female genital area; K - Male genital organ; L - Male pedipalp, dorsal view. Scale lines: 1.0mm (Figs. F, L), 0.5mm (Fig. A), 0.4mm (Figs. B, G-K), 0.05mm (Figs. C-E). 
without pedicel 1.00-1.10 (1.71-1.72), movable finger length $0.63-0.65(0.59-0.63 \times$ hand $)$; leg I: femur $0.33-0.35 / 0.25-0.27$ (1.30-1.32), patella $0.58-0.60$ / 0.23-0.25 (2.40-2.52), tibia $0.50-0.55 / 0.15-0.17$ (3.24-3.33), tarsus $0.38-0.45 / 0.12-0.14$ (3.173.21); leg IV: femur + patella 1.05-1.15 / 0.38-0.40 (2.76-2.88), tibia $0.75-0.80 / 0.22-0.25(3.20-3.41)$, tarsus $0.50-0.55 / 0.14-0.15(3.57-3.67)$.

Female: Body length: 5.40-6.20. Carapace 1.20 $1.25 / 0.95-1.00$ (1.25-1.26); pedipalp: trochanter 0.50-0.60 / 0.35-0.40 (1.43-1.50), femur 0.95-1.00/ $0.40-0.44$ (2.27-2.38), patella $0.95-1.00 / 0.47-0.52$ (1.92-2.02), chela with pedicel 1.75-1.80 / 0.60-0.65 (2.77-2.92), chela without pedicel 1.55-1.62 (2.49$2.58)$, hand without pedicel 1.00-1.03 (1.58-1.67), movable finger length $0.63-0.65(0.63 \times$ hand $)$; leg I: femur $0.30-0.32 / 0.25-0.26$ (1.20-1.23), patella $0.55-0.57 / 0.23-0.25(2.28-2.39)$, tibia $0.50-0.55 /$ 0.15-0.18 (3.06-3.33), tarsus $0.42-0.45 / 0.10-0.12$ (3.75-4.20); leg IV: femur + patella 1.05-1.10 / 0.40 0.45 (2.44-2.63), tibia $0.65-0.70 / 0.21-0.25$ (2.80 $3.10)$, tarsus $0.50-0.55 / 0.13-0.15$ (3.67-3.85).

Distribution: China (Hainan Island).

Habitat: Atemnus limuensis sp. nov. was collected from under an Ormosia tree bark in a humid tropical forest.

Remarks: Atemnus limuensis sp. nov. differs from A. letourneuxi in its large size and the presence of strong granules on the prolateral face of the chelal patella. Atemnus neotropicus from Puerto Rico is known only from a female, which differs from females of $A$. limuensis sp. nov. in having a small size (body length $4.10 \mathrm{~mm}$ ), light in color, the presence of weak eyespots and rounded dorsal protuberances on the chelal trochanter. Atemnus strinatii can be distinguished from A. limuensis sp. nov. in having round dorsal tubercles on the chelal trochanter, without eyespots and with weakly granulate chelal femur and patella. Atemnus limuensis sp. nov. differs from $A$. syriacus by the slender pedipalp (male femur 2.22-2.55 $\times$, patella 2.12-2.18 $\times$, chela with pedicel $2.97-3.10 \times$, chela without pedicel $2.73-2.84 \times$, hand without pedicel 1.71-1.72 $\times$ versus femur $2.1 \times$, patella $1.7 \times$, chela with pedicel $2.6 \times$, chela without pedicel $2.3 \times$ as long as broad in A. syriacus) and the absence of a brown band on carapace.

Atemnus politus can be easily be separated from $A$. limuensis sp. nov. by the slimmer male genital organ
(Figs. $1 \mathrm{~K}, 2 \mathrm{~K}$ ): the ejaculatory canal atrium (e) is not well-developed and may be aberrant in A. politus; but in A. limuensis sp. nov., the atrium is normal, crescent-shaped on either side, and the distal end of the atrium is typically procurved. Moreover, the distal part (1) of lateral apodemes (a) in A. limuensis sp. nov. is larger than that in A. politus. However, they have many congeneric characters in the male genitalia (the letters refer to those of Figs. 1K and 2K): (1) the sclerotized distal part of lateral apodemes; (2) the presence of a hooked branch on proximal part of the lateral apodemes; (3) the presence of a rugose darker area on proximal part of the lateral apodemes; (4) the presence of a round projection on medial diverticulum and a prominent extension along the sagittal plane in M-shaped bulge ( $\mathrm{k}$ ) on two medial diverticula; (5) the long and proximally diverging lateral rods; (6) the distally joined long dorsal apodeme; and (7) the presence of bilobed anterior wall on the ventral diverticulum.

\section{REFERENCES}

Beier,M.(1932a).RevisionderAtemnidae(Pseudoscorpionidea). Zoologische Jahrbücher, Abteilung für Systematik, Ökologie und Geographie der Tiere 62: 547-610.

Beier, M. (1932b). Pseudoscorpionidea II. Subord. C. Cheliferinea. Tierreich 58: i-xxi, 1-294.

Beier, M. (1955). Über Pseudoscorpione aus Syrien und Palästina. Annalen des Naturhistorischen Museums in Wien 60: 212-219.

Beier, M. (1963). Ordnung Pseudoscorpionidea (Afterskorpione). In Bestimmungsbücher zur Bodenfauna Europas, Vol. 1. Akademie-Verlag, Berlin.

Beier, M. (1967). Pseudoscorpione vom kontinentalen SüdostAsien. Pacific Insects 9: 341-369.

Canestrini, J. (1884). Chernetidi Italiani. In: Berlese, A. (ed.), Acari, Myriapoda et Scorpiones hucusque in Ita reperta, vol. fascicolo 10. A. Berlese: Padova.

Chamberlin, J.C. (1931). The arachnid order Chelonethida. Stanford University Publications, Biological Sciences 7(1): $1-284$.

Chamberlin, J.C. (1933). Some false scorpions of the atemnid subfamily Miratemninae (Arachnida - Chelonethida). Annals of the Entomological Society of America 26: 262 268.

Dashdamirov, S. \& W. Schawaller (1992). [Pseudoscorpions of the Caucasian fauna (Arachnida Pseudoscorpionida)]. Arthropoda Selecta 1(4): 31-72.

Harvey, M.S. (1991). Catalogue of the Pseudoscorpionida. Manchester University Press: Manchester, 726pp. 
Key to Atemnus species

1. Hand length without pedicel equal or more than $1.00 \mathrm{~mm}$.

A. limuensis sp. nov.

- $\quad$ Hand length without pedicel less than $1.00 \mathrm{~mm}$

2. Only pedipalpal femur with granulations; tarsus of leg IV $3.2 \times$ longer than broad

- $\quad$ All segments of pedipalps with granulations; tarsus of leg IV $3.8 \times$ longer than broad

A. letourneuxi (Simon, 1881)

3. Eyespots absent

3

- $\quad$ Eyespots present

A. strinatii Beier, 1977

4. Pedipalpal femur more than $2.2 \times$, patella more than $2.0 \times$ and chela $2.4 \times$ longer than broad; carapace

_ $\quad$ Pedipalpal femur less than $2.2 \times$, patella less than $2.0 \times$ and chela less than $2.4 \times$ longer than broad;

carapace frequently with dark transverse band ............................................ A. syriacus (Beier, 1955)

5. Eyespots distinct.

A. politus (Simon, 1878)

- $\quad$ Eyespots indistinct.

A. neotropicus Hoff, 1946

Harvey, M.S. (2011). Pseudoscorpions of the World, version 2.0., Western Australian Museum, Available from: http:// www.museum.wa.gov.au/catalogues/pseudoscorpions/ (accessed 27 October 2011).

Hoff, C.C. (1946). New pseudoscorpions, chiefly neotropical, of the suborder Monosphyronida. American Museum Novitates 1318: 1-32.

Judson, M.L.I. (2007). A new and endangered species of the pseudoscorpion genus Lagynochthonius from a cave in Vietnam, with notes on chelal morphology and the composition of the Tyrannochthoniini (Arachnida, Chelonethi, Chthoniidae). Zootaxa 1627: 53-68.

Judson, M.L.I. (2010). A review of K. Kishida's pseudoscorpion taxa (Arachnida, Chelonethi). Acta Arachnologica 59(1): 9-13.
Kishida, K. (1929). [On the criteria to classify chelifers]. Lansania 1(8): 124.

Klausen, F.E. (2005). The male genitalia of the family Atemnidae (Pseudoscorpiones). Journal of Arachnology 33: 641-662.

Murthy, V.A. \& T.N. Ananthakrishnan (1977). Indian Chelonethi. Oriental Insects Monograph 4: 1-210.

Simon, E. (1878). Liste des espèces de la famille des Cheliferidae qui habitant l'Algérie et le Maroc. Annales de la Société Entomologique de France (5)8: 144-153.

Simon, E. (1881). Descriptions d'Arachnides nouveaux d'Afrique. (Chernetes de la Basse Égypte rec. par M. Letourneux). Bulletin de la Société Zoologique de France 6: $1-15$. 